\title{
La percepción de los acontecimientos políticos españoles de enero a julio de 1936 en la prensa inglesa
}

\author{
Miguel FERnÁNDEZ-LONGORIA
}

\section{The perception of Spanish political events (Jannuary-July 1936) in the English newspapers}

\begin{abstract}
RESUMEN
Este articulo presenta la visión que la prensa británica de los acontecimientos políticos españoles de enero a julio de 1936. Los medios cercanos a la ideología conservadora asemejaron la caótica situación en España con la rusa prerevolucionaria. Esta interpretación de la realidad española vino a coincidir y reforzar la percepción de los círculos gubernamentales y del Foreign Office, influyendo decisivamente en la postura británica ante la Guerra Civil española.

Por su parte, la prensa ligada al movimiento obrero, presentó los desórdenes y las huelgas como actos de resistencia obrera.
\end{abstract}

\section{PALABRAS CLAVE:}

Segunda República, Relaciones hispanobritánicas, Prensa, Frente Popular, Comunismo, Foreign Office, Percepción.

\begin{abstract}
This article presents the British newspapers's perception of the political events in Spain from January 1936 to July 1936. Conservative media believed that the situation resembled the prerevolutionary Russia. This understanding of the Spanish reality agreed with the government and Foreign Office perception, influencing the British policy towards the Spanish Civil War. The leftwing media presented the disturbances and the strikes as labour's resistance actions.
\end{abstract}

\section{KEYWORDS:}

Second Republic, Spain-Britain Relations, Press, Popular Front, Communism, Foreign Office, Perceptions.

Desde la revolución de octubre de 1934, los acontecimientos políticos españoles tuvieron una mayor cobertura en la prensa británica. En los meses previos al estallido de la guerra civil los periódicos ingleses comenzaron a publicar de manera regular artículos sobre la situación política en España. Fundamentalmente, debido al continuo flujo de noticias relacionadas con los desórdenes, asesinatos y huelgas que se produjeron después del triunfo electoral del Frente Popular en las 
elecciones de febrero de 1936. El resultado fue que la opinión pública británica se fue polarizando ante la evolución política española en torno a dos extremos bien diferenciados, preparando el camino para la propaganda de los años de la Guerra Civil.

De esta manera, la derecha interpretó que en España existía un ambiente prerevolucionario, donde anarquistas, socialistas y comunistas buscaban liquidar el orden existente. A sus ojos, de no cambiar el rumbo de la vida política y social del país, pronto se desatarían todos los horrores de la revolución rusa. Además, como la evolución política española ponía en peligro los intereses económicos británicos, fueron especialmente sensibles a las medidas de carácter laboral tomadas por el Frente Popular y su incapacidad para frenar la oleada de huelgas que afectó a España durante aquellos meses. Por otro lado, la izquierda, consciente de los desastres que habían experimentado las organizaciones obreras en Alemania, Austria e Italia, juzgó que los desórdenes que se producían en el país eran actos de resistencia obrera ante el avance del fascismo, siendo un intento heroico del proletariado por alcanzar el poder.

Hay que señalar la existencia de opiniones más moderadas en la prensa británica que defendían que la victoria del Frente Popular no significaba que habría una revolución en España. Sin embargo, incluso estos diarios indicaron que el rasgo principal que definía la situación de España en esos meses cruciales fue «la revolución de las masas", parafraseando a Ortega y Gasset, que utilizando distintos medios de presión, como las huelgas, pretendían acelerar el proceso de reformas emprendido por el Frente Popular. En cualquier caso, incluso la prensa más moderada era consciente de que si no se avanzaba rápidamente por el camino de las reformas, los trabajadores españoles optarían por la revolución. A continuación se exponen las principales líneas de pensamiento de la prensa británica ante los acontecimientos políticos españoles en los meses previos al estallido de la Guerra Civil, desde enero a julio de 1936'.

\section{LA AMENAZA DE LA REVOLUCIÓN COMUNISTA}

La percepción de los acontecimientos que se desarrollan en España durante los primeros meses de 1936 llevó a que parte de la prensa británica considerase que el país se encontraba inmerso en un auténtico periodo prerrevolucionario. La formación del Frente Popular se recogió con inquietud, pues confirmaba el peligro de una posible revolución comunista, al identificarse el frente de izquierdas con un frente marxista. Ante los resultados de las elecciones de febrero de 1936, los periódicos más conservadores se preguntaron si España terminaría convirtiéndose en

1 Para la elaboración de este trabajo se ha consultado la siguiente prensa periódica durante dicho periodo: The Times, The Daily Herald, The Daily Telegraph, The Daily Worker, The Economist, The Daily Maily The Manchester Guardian. 
un régimen bolchevique ${ }^{2}$. Para estos medios, el entusiasmo popular y los desordenes desatados tras el triunfo del Frente Popular no se podian comparar con las "pacíficas manifestaciones de 1931 ". Sobre todo, porque en las manifestaciones de 1936 se desfilaba con el puño en alto cantando La Internacional en lugar de La Marsellesa. A partir del triunfo del Frente Popular en las elecciones, la prensa moderada y conservadora se dedicó a mostrar la creciente agitación obrera, que se tradujo en un incremento de episodios de desórdenes y violencia ${ }^{3}$. Al recogerlos en sus páginas, pudieron ilustrar que España había entrado de lleno en un periodo prerrevolucionario.

A partir de ese momento, la prensa conservadora británica se dedicó a utilizar imágenes de la revolución rusa para interpretar los acontecimientos que sucedían en España. Así, el Daily Mail se preguntaba si Largo Caballero, en el papel de Lenin, habría elegido a Azaña para el papel de Kerensky. Esta analogía aparecería recurrentemente en la prensa conservadora, no sólo en sus artículos sino también en las opiniones de los lectores ${ }^{4}$. Lógicamente, la ola de violencia que sacudía a España fue utilizada para apoyar sus argumentos y comparar ambas situaciones. Por ejemplo, se criticaba que "en Barcelona hubiera más pistoleros que en Petrogrado en $1917 \aleph^{5}$. Otra imagen de la revolución rusa como es la confraternización entre obreros y soldados, también fue reflejada en estos medios. Asi, The Times describió como los guardias de asalto que se dirigían a dispersar a los manifestantes que celebraban el triunfo electoral del Frente Popular no sólo desobedecieron las órdenes de sus oficiales, sino que "se unieron a la manifestación y con el puño en alto demandaron la amnistía de los presos políticos»" Estos episodios sivieron de fundamento para la censura de la creciente politización de las fuerzas de seguridad del Estado. De este modo, se alimentaba la opinión de que España estaba bajo la amenaza de una revolución comunista. Paralelamente, comenzaron a recoger rumores acerca de la existencia de preparativos de golpes de estado liderados por monárquicos o militares. La posible reacción de la derecha ante todos los episodios de violencia y anarquía que se vivían en España aparecía parcialmente justificada ante dicha situación.

El peligro de que el triunfo de la revolución en España pudiera extender el comunismo a otras zonas geográficas fue recogido como otra gran señal de alarma por la prensa conservadora y moderada. Esto explica que se hicieran eco del temor

\footnotetext{
${ }^{2}$ Los periódicos más conservadores, el Daily Mail y el Daily Telegraph, destacaban por su feroz anticomunismo.

${ }^{3}$ Periódicos más moderados como el Times o el Manchester Guardian dieron una interpretación más ecuánime de los acontecimientos, aunque enfocados desde posiciones más o menos conservadoras. La prensa económica consultada, The Economist, mantuvo posiciones moderadas por lo que sus opiniones han sido agrupadas con las de los diarios anteriormente mencionados.

4 Lord Queenborough escribió en el Daily Telegraph el día 26 de febrero de 1936 que Azaña iba a desarrollar el papel de un nuevo Kerensky, manifestando su preocupación de que significara que el sueño de Trostky de tener una Europa uroja" en ambos extremos se hiciese pronto realidad. Esta carta fue contestada al dia siguiente por M. Gabarro Garcia, quien refutó sus argumentos.

5 The Manchester Guardian, 20 de abril de 1936, p. 15.

6 The Times, 18 de febrero de 1936, p. 14.
} 
de las autoridades francesas de que la violencia que se producía en España se extendiera al Marruecos francés, y que se recogiese la existencia de agitación sindical provocada por comunistas españoles en Tánger. Este tipo de problemas daba una nueva dimensión a la situación española, ya que también amenazaba con crear tensiones en el ámbito internacional. Los principales argumentos que causaron la alarma de la prensa conservadora y moderada británica fueron los siguientes:

\subsection{El avance del comunismo en España}

La formación del Frente Popular, identificado desde su nacimiento como un frente marxista, supuso la confirmación del peligro de que se produjese una revolución comunista en España. De esta manera, durante la contienda electoral estos medios se dedicaron fundamentalmente a exaltar su carácter revolucionario a través de las declaraciones de sus líderes, especialmente de Largo Caballero, y su propaganda electoral, cargada de mensajes revolucionarios. Estos medios expresaron su repulsa ante los carteles electorales utilizados por el Frente Popular en los que se representaban a hombres y mujeres muriéndose de hambre, puertas de prisiones o cadáveres ahorcados en árboles. Además, es revelador que se mencionara que por primera vez en España se estaba llevando a cabo abiertamente propaganda bolchevique a través de un manifiesto firmado por los «amigos de Rusia", pidiendo el voto por el sistema soviético que "irradia paz, progreso y prosperidad" 7 . Tanto antes como después del periodo electoral describieron profusamente la creciente presencia de la simbología comunista, tales como el color rojo, la hoz y el martillo, el saludo con el puño en alto, o retratos de Lenin, Stalin, Thaelmann, Prested y otros héroes "rojos" en las distintas manifestaciones del Frente Popular. Pronto observaron como las demostraciones de fervor marxista se extendieron a las Cortes, donde los diputados del Frente Popular entonaron La Internacional con el puño en alto en diversas ocasiones. Por estas razones, ante la votación del día 16 de febrero estos medios se preguntaban si España se convertiría en el segundo estado socialista del mundo. De este modo, planteaban las elecciones españolas como una disyuntiva entre democracia y comunismo, en la que planeaba la amenaza de la revolución.

Al producirse la oscilación política de la República hacia la izquierda en medio de una ola de violencia, el temor a una revolución comunista se hizo más patente. La prensa conservadora creía que el objetivo de los extremistas de izquierda era la destrucción de las instituciones existentes por medio de la violencia, y la implantación de la dictadura del proletariado. En este sentido, denunciaban que la doctrina subversiva que se había puesto en práctica en la revolución de octubre de 1934, volvía a ser difundida en España por los partidos socialista y comunista. De

7 Curiosamente el mismo día que se mencionaba la existencia de propaganda soviética en España, The Times advertía a sus lectores sobre la existencia de propaganda comunista en la India. The Times, 14 de febrero de 1936, p. 13. 
acuerdo a su interpretación, ambas formaciones políticas, siguiendo las doctrinas de Lenin y Marx, creían que la conquista del poder era un requerimiento inmediato del socialismo español. Las crecientes actividades de las milicias comunistas, demandando dinero para armas, y las declaraciones de líderes extremistas eran prueba de ello. De este modo, recogieron discursos como el de La Pasionaria en el que afirmaba que lo que estaban viviendo "era un periodo revolucionario, que no debía ser detenido por meras consideraciones legales" ${ }^{8}$.

El aumento de las actividades relacionadas con España del Komintern, tildada de organización revolucionaria internacional, mostraba que la revolución comunista era inminente. En este sentido, el Daily Telegraph recogió en sus páginas la presencia de agitadores comunistas, como Bela Kun, que «habían llegado a España como agentes de la Rusia soviética para dirigir a los extremistas y preparar la insurrección comunista", o la llegada de los exiliados de Rusia, de los que se decia que «habian sido entrenados en métodos revolucionarios". La prensa conservadora reforzó sus argumentos con declaraciones de Calvo Sotelo en las que alertaba del "peligro rojo en España». En su opinión, «Rusia estaba deseando ver la creación de un segundo régimen soviético, siendo sus intenciones involuntariamente apoyadas por aquellos que se autodenominan intelectuales y burgueses, y que, por ganar unos asientos en las Cortes, han despertado las ambiciones marxistas con la creación del Frente Popular ${ }^{10}$.

En resumen, el mensaje transmitido por los medios conservadores indicaba que en España existía una guerra civil latente, ya que comunistas disfrazados de republicanos, que recurrían a la violencia si lo consideraban necesario, se estaban preparando para otra revolución.

\subsection{La radicalización del partido socialista}

La prensa británica conservadora y moderada lamentó que el partido socialista hubiese abandonado su línea evolucionista para defender la vía revolucionaria. En este sentido, apuntaban que en el partido socialista ya no se oian las voces de los Moderados, como Fernando de los Ríos, sino las de Largo Caballero, «el Lenin español", o las de Luis Araquistain, "el paladín de la Unión Soviética». Para estos diarios, solo la clara tendencia bolchevique dominante dentro del partido socialista había permitido que se alcanzara el acuerdo con los comunistas y anarquistas de cara a las elecciones de febrero.

El hecho de que Largo Caballero y sus seguidores hubieran abandonado todo intento evolucionista creando un nuevo programa y desafiando a la dirección del partido dominada por los Moderados, fue visto con preocupación por estos medios.

- Aparecidas en The Times, 3 de marzo de 1936, p. 13.

9 The Daily Telegraph, 27 de marzo de 1936, p. 13.

10 The Daily Telegraph, 24 de abril de 1936, p. 13. 
Sobre todo, porque su manifiesto contaba con el apoyo de dos tercios de las bases y defendía la dictadura del proletariado como un estado necesario en la transición del capitalismo al estado socialista. Además, se hacían eco de los ataques de los grupos socialistas más extremistas a Prieto y a su grupo de Moderados. Estos últimos estaban a favor de conseguir una legislación más progresista pero no a través de métodos revolucionarios. En este sentido, recogieron declaraciones como las de Calvo Sotelo en las que advertía a los británicos que "los socialistas españoles no eran como sus homólogos belgas o ingleses, ya que en España el 90 por ciento de ellos defendían tácticas revolucionarias y buscaban implantar la dictadura del proletariado» "11.

\subsection{La ola de violencia y anarquia}

Para estos medios, el movimiento obrero presionaba al Gobierno para que avanzase por el camino de las reformas, ignorando las lamentables condiciones económicas del país y la tensa situación política. Se creía que Largo Caballero y el resto de líderes revolucionarios intentaban imponer muchas de las medidas defendidas por socialistas y comunistas que no habian sido incluidas en el programa electoral del Frente Popular. A pesar de todas las medidas que el nuevo Gobierno había llevado a cabo desde febrero, la prensa conservadora observaba que éstas no habian conseguido saciar el apetito de la extrema izquierda, que provocaba continuos desórdenes para conseguir sus demandas.

Los periódicos moderados y conservadores vieron con gran preocupación la nueva ola de violencia que se abatía sobre la República, recogiendo en sus noticias los numerosos incidentes que se produjeron por toda España tras la victoria electoral del Frente Popular. A partir de entonces, las noticias de desórdenes, asesinatos, ataques a la propiedad privada y a la Iglesia, aparecieron casi a diario en algunos periódicos ${ }^{12}$. En algunos casos se incluyeron reportajes gráficos sobre la destrucción de iglesias o de disturbios del orden público. Estos medios vieron como la anarquía comenzaba a reinar en España, siendo las autoridades incapaces de contener la violencia, que comenzaba a degenerar en asesinatos por motivos políticos. Hay que resaltar que periódicos como The Times, The Daily Maily The Daily Telegraph incluyeron los informes que Calvo Sotelo y Gil Robles ofrecían regularmente en las Cortes contabilizando los actos de violencia en España. Los métodos utilizados en los ataques a iglesias y conventos les indicaban que eran actos organizados llevados a cabo por elementos anarquistas y comunistas. Para estos medios, este tipo de actuación era la puesta en práctica de la teoría de

1 Declaraciones recogidas por el Daily Telegraph, 4 de marzo de 1936, p. 14.

12 Titulares como "Arson and rioting in Spain", "Shots at socialists", "Spain menaced by extremist disorders", "Violence in Spain", "Communist threat to Madrid" o "Spanish nuns flee to Gibraltar" aparecen en periódicos como The Times, The Daily Telegraph, The Daily Mail y The Manchester Guardian durante el mes de marzo de 1936. 
Trostky de revolución permanente. Además, relataban como la atmósfera de tensión y alarma causada por el incremento de la violencia estaba provocando la huida de muchos españoles a Portugal, Francia o Gibraltar.

La prensa moderada opinaba que la agitación y el desorden enturbiaban el panorama político y que se necesitaba más mano dura frente a las masas descontroladas. Según estos medios, el mantenimiento de la ley y el orden era el primer paso para la reconciliación de España. En este sentido, los discursos de Azaña o Casares Quiroga, donde manifestaban que defenderían la legalidad existente fueron considerados como muy positivos. Sin embargo, al producirse actos violentos de forma continuada, se perdió la confianza en que el gobierno republicano pudiera remediar la situación.

Las medidas tomadas por el gobierno del Frente Popular contra los desórdenes, como la vigilancia de iglesias y el arresto de miembros de Falange, se consideraban insuficientes, indicando que las autoridades debían mostrar más firmeza en los disturbios. Concretamente, criticaban que la mayoría de las medidas adoptadas para frenar la violencia política, como la ilegalización del partido fascista o las acciones disciplinarias contra oficiales de la guardia civil que habían participado en manifestaciones de Falange, se centraban en someter a los extremistas de la derecha, mientras que no se ponía coto a la violencia generada por los extremistas de la izquierda. La prensa moderada también criticaba que la censura de prensa era extremadamente represiva con los periódicos de la derecha, mientras que se permitía que los órganos de expresión de la izquierda más extremista predicaran la revolución y la violencia.

Dentro del panorama de anarquía y caos que reinaba en el país, dos hechos significativos confirmaron a estos medios que la situación política española era extremadamente peligrosa. El primero fue la muerte de un ciudadano británico en Barcelona, Jack Hood Mitchell, director de la firma La Escocesa, cuyo asesinato conmocionó a la opinión pública británica. Este empresario fue asesinado por un anarquista al negarse a readmitir a unos trabajadores que había despedido en 1933 por atentar contra la maquinaria de su empresa. El segundo fue el asesinato de Calvo Sotelo, que llevó a estos medios a afirmar que en España tanto la vida de las personas como la propiedad estaban seriamente en peligro ${ }^{13}$. Estos dos episodios mostraron que la violencia de los extremistas de izquierdas ya no tenia límites en su lucha por instaurar en España el estado socialista. Al considerar que el Gobierno era incapaz de frenar la ola de violencia que se venía extendiendo desde las elecciones de febrero, la prensa británica desconfió aún más de la labor del

${ }^{13}$ El asesinato de Calvo Sotelo recibió amplia cobertura de prensa. Los medios conservadores y moderados indicaron que fue un acto de venganza cometido por guardias de asalto tras el asesinato del teniente Castillo, señalando que el propio Calvo Sotelo era contrario al uso de la violencia. El periódico The Times incluso incluyó una columna necrológica, y el Manchester Guardian le señaló como la única persona que hubiese podido liderar el fascismo español. Así mismo, todos los medios coincidieron en reflejar sus críticas al Gobierno por no impedir los asesinatos políticos y por su permisividad ante aquellos cometidos por la izquierda. 
gobierno republicano y de su capacidad para poner freno al periodo revolucionario que, en su opinión, comenzaba a desatarse en España.

\section{LA LUCHA CONTRA EL FASCISMO EN ESPAÑA}

La prensa ligada al movimiento obrero interpretaba los acontecimientos de un modo muy diferente ${ }^{14}$. Para estos medios, lo que en realidad sucedia era que la República española estaba luchando por su existencia contra la amenaza del fascismo. Gil Robles era presentado como el gran enemigo de la libertad, por las medidas que había tomado contra los trabajadores durante la legislatura anterior. $\mathrm{Si}$ alcanzaba de nuevo el poder, la prensa obrera opinaba que España se uniría al grupo de países fascistas europeos, junto a Italia y Alemania. Ante esta situación, alertaban que los obreros españoles no sucumbirian al terror sin lucha, por lo que habría una nueva revuelta en España. Por esta razón, la formación del Frente Popular, donde los partidos obreros acudieron a las urnas junto a los partidos republicanos de izquierdas, fue vista como una iniciativa muy positiva, ya que se esperaba que evitase el triunfo del fascismo en las elecciones. Estos medios consideraban que en dicha votación los españoles iban a elegir entre la República o un régimen clerical-fascista. En este sentido, recogieron diversas manifestaciones en las que los principales líderes de los partidos de la izquierda, como Largo Caballero, señalaban que «la victoria de la derecha en las elecciones de febrero significaría la implantación de una dictadura en España» ${ }^{15}$.

Por lo tanto, estos medios interpretaron el triunfo del Frente Popular en dichas elecciones como "una gran victoria de la democracia» o «un triunfo del pueblo», considerando que los obreros españoles habian votado decisivamente para la defensa de la República, para la restauración de la libertad, la amnistía y el progreso. Para la prensa obrera este triunfo de la izquierda española también probaba el éxito de la táctica de un frente común contra el fascismo. El éxito del Frente Popular fue considerado como una gran victoria para las fuerzas antifascistas de toda Europa, ya que se produjo en un momento en el que el movimiento obrero había sido desmantelado en Italia, Austria y Alemania ${ }^{16}$. Aunque reconocían que no significaba la implantación del socialismo, celebraron la derrota del fascismo-clerical de Gil Robles, de los grandes propietarios, de los millonarios de la industria y de la Iglesia.

Para estos medios, las emotivas escenas que se vivieron tras el triunfo electoral fueron una repetición de la alegría que invadió al país en 1931 cuando Alfonso XIII fue forzado a huir de España. Aunque se hicieron eco de los desórdenes que

${ }^{14}$ La prensa obrera analizada, el socialista Daily Herald, y el comunista Daily Worker, dieron su apoyo a sus camaradas españoles.

15 The Daily Herald, 15 de febrero de 1936, p. 3.

${ }^{16}$ Durante los meses de febrero y marzo, el Daily Herald publicó 18 artículos de John L. Spivak sobre el terror fascista en Europa. 
siguieron a las elecciones, tan sólo los mencionaron como disturbios sin importancia, sin describir en que habían consistido. Lógicamente, se mencionó con satisfacción como la policía se negó a cargar contra los manifestantes que celebraban con alegría el triunfo del Frente Popular. La prensa obrera disfrutaba viendo como el pánico se había apoderado de la derecha, criticando los intentos de Gil Robles por retrasar o impedir el traspaso de poderes a la izquierda, y como esta ola de pánico estaba también provocando que la aristocracia huyera del país. Estos periódicos mostraron numerosas fotografías de partidarios del Frente Popular festejando el triunfo electoral. Hay que señalar que cada diario apoyaba a su respectivo grupo político en España, coincidiendo ambos en destacar el importante papel del voto anarquista en las elecciones.

A pesar de la victoria de la izquierda, presuponían que la tarea del nuevo gobierno no era fácil, ya que debía dominar a la banca, romper los grandes latifundios en beneficio de los campesinos, cambiar las altas esferas del ejército para garantizar su lealtad, y realizar una profunda reforma de la educación. De la misma manera, se apuntaba que la izquierda quería triunfar debía hacer frente a los viejos prejuicios y colaborar entre sí, olvidando las grandes diferencias que les separaban, si querian sobrevivir a los ataques de sus enemigos. Estos medios consideraban que la derecha disponía todavía de numerosos recursos y que intentaría aprovechar cualquier debilidad de la izquierda para volver al poder. Para la prensa obrera, la izquierda española tenía gente preparada para llevar a cabo el reto al que se enfrentaban. El Daily Herald presentaba a Azaña como la figura más sobresaliente de la nueva España, ya que «contaba con un gran carácter, energía y determinación». Largo Caballero era la otra gran figura, «el gran líder sindical, agresivo que nunca dejaba de luchar», ensalzado tanto por la prensa socialista como por la comunista. Además, destacaba a Prieto y a Fernando de los Rios, al que se define como "uno de los más nobles intelectuales de Europa» "17. Por su parte, la prensa comunista destacaba la figura de La Pasionaria. Según estos medios, todos ellos tenían la inmensa responsabilidad de consolidar el triunfo de la izquierda, en lo que se creía que era la última oportunidad del constitucionalismo en España.

La prensa obrera celebró la amnistía de los detenidos por la revolución de octubre de 1934, pues terminaba la injusta detención de miles de personas y permitía la vuelta a España de los exiliados políticos. De esta manera, las victimas del terror en España comenzaban a ver justicia, al ser liberados de la prisión y al ser readmitidos en sus puestos de trabajo. La prensa obrera incluyó numerosas fotografías de los prisioneros políticos siendo liberados. Para estos medios, el gran movimiento de masas que se desató en España tras la victoria del Frente Popular evitaba que los reaccionarios tuvieran una nueva oportunidad de atacar a la República.

17 Todas estas semblanzas aparecen en el diario socialista The Daily Herald el dia 22 de febrero de 1936. 
Respecto a la ola de violencia en España, para la prensa obrera los únicos culpables de la misma eran los fascistas. Estos medios señalaban con indignación que las fuerzas reaccionarias estaban conspirando contra la victoria de los trabajadores. Por esta razón pensaban que la mejor respuesta para la defensa de la República era la movilización obrera, mediante la cual los propios trabajadores debían tomar precauciones para prevenir un nuevo asalto de las fuerzas conservadoras. De este modo, los asaltos a iglesias estaban justificados, dado que los conspiradores guardaban armas en su interior. Los fascistas también eran considerados como los responsables de la escalada de tensión que supusieron los asesinatos del teniente Castillo y de Calvo Sotelo ${ }^{18}$. Estos medios valoraron positivamente las medidas del Gobierno por las que se detuvieron a numerosos fascistas y se clausuraron sedes de los partidos de derechas. En su opinión, dichas medidas abortaron la intentona fascista más seria para hacerse con el poder desde 1934. Para estos periódicos, los trabajadores reaccionaron antes de que se produjera dicho acontecimiento y atacaron las sedes de los partidos monárquicos y de la CEDA, impulsando al Gobierno para que realizarse dichas detenciones.

En cuanto a la política española, la prensa obrera aplaudió las medidas de reforma aprobadas por el gobierno del Frente Popular, especialmente la amnistía y la readmisión de los trabajadores despedidos desde enero de 1934. Estos medios apreciaban que era el pueblo el que tomaba la iniciativa y empujaba las reformas, como había sucedido con la liberación de los presos o las ocupaciones de fincas. Además, valoraban que la reacción del Gobierno no fuese el envío de la guardia civil o del ejército, sino la rectificación de la situación que había motivado la actuación del pueblo. Según su opinión, la clase obrera presionaba al gobierno de la República porque no podía aguantar más la mísera situación en la que vivía. La situación de extrema pobreza, junto a un nivel salarial extremadamente bajo, motivaba a los trabajadores españoles a luchar para evitar morirse de hambre. Obviamente, para estos periódicos el único remedio ante el enfrentamiento entre capitalistas y trabajadores era el socialismo.

Respecto a las tácticas que debía desarrollar el movimiento obrero, el Daily Worker señalaba que el partido comunista debía apoyar al Gobierno sólo si se llevaban a cabo todas las medidas incluidas en el programa electoral del Frente Popular. Sin embargo, este medio significaba que el golpe final contra el fascismo, la liquidación de las organizaciones reaccionarias o la expropiación de la tierra sólo las podían llevar a cabo las clases trabajadoras y no un gobierno que no era totalmente comunista. Por esta razón, se exhortaba al partido comunista para que organizase a los obreros con el fin de presionar para que acelerase el cumplimiento del pacto electoral. Para conseguirlo creían que era necesaria «la preparación de los trabajadores de cada fábrica, empresa y pueblo». En este sentido, se citaban ejemplos de cómo el partido comunista llevaba a cabo esta política. Así, se men-

18 La prensa obrera dio mayor cobertura al asesinato del teniente Castillo. Calvo Sotelo fue calificado como la persona que podia haber liderado el movimiento fascista español. 
cionaba cómo en la provincia de Cáceres se había incitado a los campesinos a que ocuparan las tierras de la aristocracia, forzando al Gobierno a aprobar una ley que acelerase la distribución de la tierra; o cómo en Granada se organizaron los obreros para desarmar a los fascistas que llevaban a cabo su campaña terrorista, motivando las detenciones de fascistas realizadas por las autoridades republicanas. En su opinión, todos estos hechos aumentaban el prestigio del partido comunista en España.

Por su parte, el Daily Herald argumentaba que tanto el futuro de España como el de Europa pasaba por el socialismo. Este medio coincidía en la defensa de la colaboración a corto plazo de los socialistas con los partidos de la izquierda republicana, para asentar el progresismo en el país. Paralelamente, creían que el partido socialista debía transmitir a la sociedad que sus ideales eran el futuro de España. La prensa obrera destacaba el acercamiento de los distintos movimientos obreros en España, viendo con esperanza la unión entre los trabajadores españoles, y valorando que los anarquistas colaborasen con el resto de organizaciones obreras. Estos periódicos se hicieron eco en sus páginas de la reunión en Londres de las asociaciones sindicales de todo el mundo en la que se apeló a la unidad de los trabajadores para combatir el peligro fascista. En dicho congreso, se destacó el papel de Largo Caballero, por su determinación en la defensa de la unión sindical y en la lucha contra el fascismo en España ${ }^{19}$.

\section{LAS MEDIDAS ECONÓMICAS DEL FRENTE POPULAR Y LA OLEADA DE HUELGAS}

La reacción de la prensa británica moderada y conservadora ante las medidas económicas planteadas por el gobierno del Frente Popular, como la implantación del salario mínimo o el establecimiento de sistemas de control sobre bancos y negocios, fue muy negativa, al ir contra sus principios de liberalismo económico. Además, la prensa era especialmente sensible a este tipo de medidas debido a los numerosos intereses económicos que Gran Bretaña tenía en España.

La medida por la cual se obligaba a las empresas a la reincorporación de los trabajadores despedidos desde enero de 1934 por causa de las huelgas políticas, fue ampliamente criticada al tener en cuenta que muchas empresas habian despedido a trabajadores por la situación económica general y no por la ideología de sus trabajadores. En este sentido, dieron numerosos ejemplos de situaciones cu-

19 En un amplio despliegue para cubrir dicho congreso, The Daily Worker incluyó una foto de Largo Caballero, transcribiéndose su discurso en el que reafirmó la determinación revolucionaria de los obreros españoles de defender la paz y de conquistar el poder. Asimismo, se mencionaba como para él la clase obrera española estaba en contra de la guerra, considerando que fue el avance del fascismo lo que empujó a los mineros asturianos a la revolución, apuntando que si la revolución hubiese tenido exito se hubiera implantado un régimen socialista en España. The Daily Worker el día 9 de julio de 1936. El Daily Herald también cubrió con detalle dicho congreso. 
riosas provocadas tras el decreto de readmisión de los trabajadores. Por ejemplo, el Daily Telegraph citaba el caso de una viuda que había tenido que readmitir en su tienda al asesino de su marido ${ }^{20}$. Lógicamente, estos medios también contaban cómo afectaba esta medida a las firmas británicas que operaban en España. En este sentido, se mencionó como la empresa Río Tinto tuvo que readmitir a 1.500 trabajadores despedidos desde octubre de 1934, mayoritariamente debido a la falta de trabajo en las minas, aunque reconocieron que algunos lo habían sido por estar implicados en la intentona revolucionaria de dicha fecha. Finalmente, puntualizaron que las empresas que realmente se verían afectadas por esta medida eran la pequeña empresa y los empresarios individuales, que eran precisamente el eje de la actividad económica española.

La oleada de huelgas que se produjo a lo largo y ancho de España recibió numerosa cobertura de prensa en el Reino Unido. Los diarios británicos mostraron cómo, aparte de afectar a sectores vitales de la economía como las comunicaciones ferroviarias y los puertos, se producian huelgas tan variopintas como las de camareros en Barcelona y Madrid, de trabajadores de campos de golf en la capital, de toreros (que paralizó la feria de Madrid), o situaciones peculiares como que los participantes de una competición ciclista se vieran obligados a unirse a una huelga general al ser considerados como «trabajadores del pedal». La prensa conservadora y moderada se escandalizó con las desorbitadas demandas de los trabajadores españoles. Como ejemplo de demandas extravagantes, The Times citaba el caso de los marinos mercantes "que pedían disfrutar de comida variada, incluyendo desde menús tradicionales a frutas exóticas»21. Según estos medios, los trabajadores envalentonados por las concesiones dadas por el gobierno republicano estaban aprovechando la situación para intentar reducir la jornada laboral e incrementar sus salarios a través de convocatorias indiscriminadas de huelgas.

Estos periódicos señalaron que este ambiente tan negativo para el mundo de los negocios estaba forzando el cierre de numerosas empresas, ya que los empresarios no podían acceder a las demandas de los trabajadores. La prensa recogió también los efectos de la ola de huelgas en la actividad de las firmas británicas en España. El caso más mencionado fue el de Río Tinto, cuya producción se paralizaba regularmente a causa de las huelgas. El Daily Telegraph mencionó el ejemplo de una firma inglesa, establecida en España desde hacía más de cincuenta años, que tuvo que cerrar debido a la fuerte presión comunista ${ }^{22}$. La situación del país fue presentada como de "terror huelguístico", ya que, aparte de la

${ }^{20}$ Aparece junto a otros sucesos relacionados con el tema en el The Daily Telegraph, 16 de abril de 1936, p. 14.

${ }^{21}$ Éstas y otras demandas definidas como "fantásticas» se describen en The Times, 5 de junio de 1936, p. 11.

${ }_{22}^{2}$ Según este medio, ante el intento por parte del empresario de reducir las horas de trabajo, los trabajadores amenazaron con hacerse con el control de la empresa y dirigirla ellos mismos con métodos soviéticos. A pesar de que el ochenta por ciento de los trabajadores estaban dispuestos a apoyar los nuevos términos, el comité de trabajadores, liderado por elementos comunistas lo rechazó, obligando a la empresa a cerrar. The Daily Telegraph, 22 de abril de 1936, p. 13. 
convocatoria indiscriminada de huelgas, en algunas ocasiones los trabajadores atacaban a las empresas, como había ocurrido en las oficinas de la Metro GoldwynMayer, mientras que en otras la situación degeneraba en pillaje.

La prensa británica observaba con aprensión como en determinadas ocasiones los trabajadores se hacian espontáneamente con el control de las empresas donde trabajaban, como había sucedido con la compañía que operaba el tranvía en la Ciudad Lineal, o con una mina en Sevilla. A pesar de la reacción gubernamental esto era un claro ejemplo de lo que podía pasar en el futuro si el Gobierno no controlaba a las masas obreras.

La oleada de ocupaciones de fincas y el nuevo impulso a la reforma agraria realizado por el gobierno del Frente Popular fue otro motivo de crítica para los medios británicos. La prensa conservadora veía con preocupación las confiscaciones de tierras realizadas a los grandes propietarios y por la manera en la que las masas campesinas tomaban la iniciativa ocupando fincas ${ }^{23}$. La prensa más moderada, ante la negativa situación en la que se encontraban las masas campesinas desempleadas, opinaba que la distribución de la tierra era una buena solución, pero que no solucionaba completamente el problema. Para The Times, a pesar de la buena intención del Gobiemo, no bastaba con distribuir la tierra, ya que muchas veces ésta no daba ni siquiera para alimentar a los campesinos por la falta de mecanización y de mercados para la venta de productos ${ }^{24}$.

\section{CONCLUSIÓN}

La mayor parte de la prensa moderada y conservadora británica interpretó que los acontecimientos políticos españoles desde enero a julio de 1936 indicaban que la situación del país se asemejaba a la rusa prerrevolucionaria. De acuerdo con su percepción de la realidad española, el país había entrado en una fase de etipo Kerenski» cuya resolución dependia de la potencia de las fuerzas revolucionaras y contrarrevolucionarias (en Rusia dicho periodo culminó con el derrocamiento del gobierno liberal de Kerenski por los bolcheviques).

Dicha conclusión, vino a coincidir y reforzar la percepción que tenía el Foreign Office y que transmitían tanto los diplomáticos acreditados en España como los residentes británicos. Desde la instauración de la República en 1931, el Foreign Office seguía atentamente los acontecimientos españoles, ya que la Península lbérica tenía un gran interés estratégico y económico para Gran Bretaña. Además, se pensaba que las autoridades republicanas podían ser victimas de la una revolución comunista, dada la conflictividad socioeconómica existente en el país. El triunfo del Frente Popular en las elecciones de 1936 aumentó en el Foreign Office el temor de

23 Tanto The Times como The Daily Telegraph estaban especialmente interesados por la suerte de las fincas que el duque de Wellington tenía en España.

24 The Times, 15 de abril de 1936, p. 9. 
que el gobierno republicano fuera sobrepasado por las fuerzas revolucionarias. Como señala Churchill, la situación en España durante la primera mitad de 1936 fue calificada de "periodo Kerenski» ${ }^{25}$ por los observadores del Foreign Office y por los círculos gubernamentales británicos, transmitida en gran parte por sus representantes diplomáticos en España ${ }^{26}$. Por su parte, la comunidad británica residente era en general opuesta a los planteamientos del Frente Popular, como demuestra que tras el estallido de la guerra civil la mayoría tuviera sus simpatías en el bando nacional ${ }^{27}$. Esto se debia fundamentalmente a que muchos de ellos eran profesionales que trabajaban para empresas británicas instaladas en España, como Río Tinto, que estaban asediadas por huelgas o eran personas adineradas con residencias en zonas costeras.

Un factor relevante que conviene destacar es que la mayoria de los periódicos británicos estaban bajo el control de empresarios o de personas de ideología conservadora, siendo las excepciones los periódicos editados por la agrupación de sindicatos, el Daily Herald, y por el Partido Comunista, el Daily Worker ${ }^{28}$. Desde un claro planteamiento ideológico, interpretaron de manera apocalíptica los acontecimientos que ocurrieron en España durante los meses previos a la guerra civil. La prensa británica ejerció una poderosa influencia sobre la imagen que los círculos gubernamentales tenían de la evolución política española. La derecha británica, influida también por factores como la simpatía de clase, la religión y el impacto de los desórdenes y huelgas, se alarmó ante el peligro revolucionario que parecía cernirse sobre España. En este sentido, conviene señalar que una gran mayoria de la derecha británica destacaba por un auténtico fervor anticomunista, y que en parte tenía cierta admiración y simpatía por los regímenes de Hitler y Mussolini ${ }^{29}$. Por su parte, la izquierda británica, a pesar de las suspicacias que despertaban ciertos sectores de la izquierda radical española como el anarcosindicalismo, se alineó con la línea de gobierno del Frente Popular, defendiendo a sus compañeros de clase en su lucha contra el fascismo en España. La prensa británica, al estar altamente polarizada, contribuyó a la opinión pública británica en los años previos a la Segunda Guerra Mundial.

25 "In fact a perfect reproduction of the Kerensky period in Russia was taking place in Spain». Mencionado en W. CHURCHILL, The Second World War, Volume 1, The gathering storm, The Folio Society, Londres, 2000.

${ }^{26}$ El Foreign Office era una institución elitista que se caracterizaba por su anticomunismo. El embajador británico en Madrid era sumamente crítico con la República. Sus opiniones eran compartidas por la mayoría de los cónsules destacados en España, entre los que destacaba por su anticomunismo el cónsul de Barcelona Norman King. TOM BuCHANAN, Britain and the Spanish civil war, Cambridge University press, Cambridge, 1997, pp. 40-42.

${ }^{27}$ Como señala K.W WATKINS en Britain divided. The effect of the Spanish Civil War on British political opinion, Thomas Nelson and Sons Ltd, Londres, 1963, que cita la opinión de C.E. Lucas Phillips, ingeniero residente en España en el momento del estallido de la contienda.

${ }^{28}$ LORD CAMROSE, London newspapers: their owners and controllers, Daily Telegraph and Morning Post., London 1939.

${ }_{29}$ Lord Rothermere, propietario del Daily Mail, ya en 1933 había alabado a los jóvenes nazis alemanes como la salvaguardia de Europa ante el peligro comunista. Daily Mail, 28 de noviembre 1933. 
En resumen, la prensa británica reforzó la percepción que tenía el Foreign Office de los acontecimientos políticos españoles, por la que se interpretaba que España había entrado en un periodo prerrevolucionario a mediados de 1936. Dicha interpretación, como sabemos, influyó gravemente en la respuesta inicial del gobierno británico ante el estallido de la Guerra Civil española ${ }^{30}$. Durante las primeras semanas de la contienda fue cristalizando en medios diplomáticos y oficiales británicos la imagen de una España sumida en un proceso revolucionario, el final de este proceso "Kerenski" que revelaba la incapacidad del gobierno español para hacer frente a la situación, especialmente al legitimar al movimiento revolucionario obrero. Dada la hostilidad existente hacia el régimen republicano en círculos gubernamentales británicos y el temor a que degenerase en un régimen comunista, existía una predilección inicial en el gobierno británico hacia una solución militar que devolviese la estabilidad a España. En consecuencia, las autoridades británicas decidieron adoptar respecto al conflicto español una posición de neutralidad. Sin embargo, al negar la asistencia a un gobierno legítimamente constituido para no favorecer por ningún medio el esfuerzo bélico republicano ni la supresión del levantamiento militar, la postura británica se convertía en benévola hacia los insurgentes.

${ }^{30}$ Siguiendo las tesis de E. Moradiellos, Neutralidad benévola, Pentalfa, Oviedo, 1990. 